\title{
APRESENTAÇÃO
}

\section{O campo minado e translúcido da segurança pública no Brasil}

\section{The mined and translucent field of public security in Brazil}

egundo o dicionário Houaiss, o adjetivo translúcido é dado a qualquer corpo que deixa passar a luz, mas $\checkmark$ que não permite que se percebam objetos colocados por detrás dele. É possível ver além, mas não de modo límpido e transparente. São formas e imagens que ficam opacas e invisíveis; ficam na sombra e por vezes mais confundem do que esclarecem.

No caso, esse adjetivo é o que melhor se aplica hoje às minadas fronteiras que delimitam tanto o campo organizacional das políticas de segurança pública implementadas nos últimos trinta anos quanto às tentativas de se avançar no conhecimento acadêmico acerca da relação entre crime, violência e justiça no Brasil.

Se olharmos para esta relação, no que diz respeito às políticas públicas de segurança, o Estado parece funcionar a partir de um forte paradoxo que nos faz lidar cotidianamente com elevadas taxas de impunidade e baixíssima capacidade de apuração e responsabilização, erodindo a confiança nas leis e nas instituições.

Por outro lado, as instituições de segurança pública e justiça criminal, premidas pelas cobranças da mídia e da opinião pública, são regidas pela ideia de que algo precisa ser feito a qualquer custo para conter os "criminosos", abrindo margens para medidas de extremo rigor e para a desconsideração de garantias, em uma dinâmica de seletividade penal que atinge, proporcionalmente, mais jovens, negros e pobres.

Nesse paradoxo, o Estado, através de seus vários poderes e instâncias, tem atuado a partir de um oneroso sistema de segurança pública, que fica recorrentemente paralisado por disputas de competência, fragmentação de políticas e jogos corporativos que respondem mais às lógicas particulares do que ao ideal de redução da violência e garantia de direitos.

O resultado é que as polícias são vistas como instituições que mais geram temor do que confiança e respeito, e o Ministério Público e o Poder Judiciário aparecem como distanciados da realidade e voltados para a punição dos mais fracos, recebendo sem maiores questionamentos o resultado do filtro realizado pelas polícias.

$\mathrm{Na}$ brecha e no cotidiano das periferias das regiões metropolitanas, o medo e a insegurança acabam fortalecendo o crime e pautando a relação entre polícia e comunidade; entre Estado e sociedade.

Não à toa, ficamos anestesiados diante da violência que, segundo os Anuários Brasileiros de Segurança Pública, resulta anualmente em quase 60 mil pessoas assassinadas, 48 mil estupros, mais de três mil mortes decorrentes de intervenção policial e quase 400 policiais assassinados. A violência nos dessensibiliza e, em vários momentos, é cultuada como resposta possível do Estado frente ao crime ou, até mesmo, como recurso legítimo frente às estruturas desiguais da sociedade brasileira.

Dito isso, observa-se que o campo que se aglutina em torno do que empiricamente tem se convencionado chamar de segurança pública é, no plano do debate político e das políticas públicas, um campo perpassado por disputas acerca do significado de lei, ordem e segurança que travam avanços pontuais na redução da violência e retroalimentam práticas institucionais e culturas organizacionais pouco democráticas. 
Porém, se deslocarmos nosso olhar para a produção acadêmica que cuida de compreendê-lo, ele é também, de forma subsidiária, palco de fortes disputas de saberes em torno da legitimidade da nomeação do que pode ou não fazer parte de suas fronteiras.

Existe hoje na Universidade uma complexa batalha epistemológica entre diferentes teorias do conhecimento e que, mais do que apenas delimitar as fronteiras do campo, coloca em jogo as balizas sobre como as Ciências Sociais interpretam a realidade contemporânea.

Por esta batalha, há uma disputa ontológica, na qual diferentes abordagens e leituras tentam delimitar qual é o objeto legítimo de estudos - violência, direitos humanos e segurança pública ou as causas estruturais da violência e da desigualdade.

Há, ainda, uma disputa discursiva acerca de quais são as regras que regulamentam os discursos que podem receber o status de científico. E, por fim, há uma disputa em torno do reconhecimento de quem são os sujeitos que podem proferir esses discursos científicos e qual o estatuto daqueles sobre quem se fala.

São oposições entre diferentes saberes que se pretendem competentes para enunciar o sentido do campo e, com isso, definir quais as fronteiras e os limites entre os diversos territórios explicativos que estão a operar no país - com implicações em agendas de pesquisas, no reconhecimento dos sujeitos do conhecimento; em linhas de financiamento e nos termos do debate público.

Historicamente, a origem destas disputas acadêmicas pode ser buscada na própria forma como se desenvolveu o campo dos estudos sobre crime, polícia e justiça no Brasil. Em um primeiro momento, eram os juristas ligados ao Direito e ao Processo Penal os que buscaram dar conta das dimensões sociológicas e criminológicas do debate sobre estes temas, tentando incorporar autores e teorias que em outros contextos foram se desenvolvendo sob a denominação de Criminologia.

Esta por sua vez, tem origem no final do século XIX e resultou em cursos de graduação e pós-graduação, especialmente no contexto anglo-saxônico, visando permitir uma formação nos diversos aspectos que envolvem o fenômeno criminal e o seu controle. No Brasil, no entanto, a Criminologia se limitou desde sempre ao espaço de uma disciplina nos cursos de Direito, geralmente ministrada por operadores jurídicos e sob influência do discurso da chamada Criminologia Crítica, que nasce nos anos 70 a partir da confluência dos estudos do Labeling Approach, da teoria marxista aplicada aos estudos das causas estruturais do crime e das relações entre punição e estrutura social.

A criminologia crítica teve grande impacto no desenvolvimento de vários estudos até a década de 1980, denunciando a seletividade penal e o papel do sistema penal como mecanismo de manutenção da ordem social em toda a América Latina, especialmente no período em que o continente era o cenário de governos ditatoriais.

Nas últimas décadas, contudo, há uma importante novidade no campo: o desenvolvimento no Brasil de uma rica vertente de estudos empíricos sobre os temas tradicionais da Criminologia, mas conduzidos não mais por juristas, e sim por pesquisadores com formação em Sociologia, Antropologia e Ciência Política, descortinando importantes evidências e trazendo complexidade a um debate científico antes dominado por apriorismos teóricos produzidos em outros contextos.

Diversos espaços de debate sobre os resultados das pesquisas realizadas por esta nova vertente foram sendo criados e viabilizaram a consolidação de uma importante rede de pesquisa, nucleada em instituições como o Instituto Nacional em Estudos Comparados em Administração de Conflitos (INEAC), o Instituto Nacional de Ciência e Tecnologia Violência, Democracia e Segurança Cidadã, o Fórum Brasileiro de Segurança Pública, entre outros centros importantes.

Essa nova vertente buscou incorporar o legado da Criminologia Crítica latino-americana e da contribuição de Michel Foucault e, ao mesmo tempo, trazer novas perspectivas teóricas, através da utilização de autores 
antes pouco considerados, como os clássicos Max Weber e Norbert Elias. Para além da das causas da violência estrutural da sociedade brasileira, ressalta a complexidade do real e identificação de atores e instituições que operam valores, éticas, normas e sentidos da violência.

Entretanto, a emergência de novos centros e núcleos de pesquisa sobre violência e segurança pública, aqui servindo de síntese empírica de diversas correntes e temas tratados nos últimos 25 anos, ampliou as possibilidades de reflexão, mas também de interação entre a Universidade, as instituições policiais e o Poder Público.

E, neste movimento, ao trazer os operadores da segurança da pública para o primeiro plano de análise, esta nova vertente os converteu em sujeitos de fala com os quais se pode discutir, mas não sem antes potencializar as fricções de uma tensa relação entre conhecimento científico e suas implicações práticas.

A despeito de progressos pontuais na aproximação de diferentes segmentos e perspectivas, as desconfianças entre e inter produtores de conhecimento acadêmico e profissionais da segurança pública são mútuas, densas e, por vezes, tensas. São inúmeras disputas pela legitimidade do saber que, mais do que contribuírem para a compreensão da realidade, estão a obnubilar o campo.

O problema é que, enquanto buscamos uma "verdade" em um campo tão minado e disputado, a violência continua a fazer milhares de vítimas todos os anos no país.

Procuramos reunir, neste dossiê, contribuições representativas da área de estudos sobre crime e violência no Brasil vem ganhando espaço na pós-graduação nos últimos 40 anos. Importantes pesquisas empíricas somadas a uma reflexão própria da realidade brasileira foram produzidas e têm contribuído para a consolidação de um profícuo debate intelectual sobre um dos eixos fundantes das Ciências Sociais e que gira em torno da análise do conflito social contemporâneo. Os estudos sobre o funcionamento das agências de segurança pública e justiça criminal em suas várias dimensões apontam para questões fundamentais do ponto de vista da compreensão dos processos de criminalização, bem como dos limites dos projetos e propostas de reforma. $\mathrm{O}$ dossiê buscava também reunir trabalhos que relacionassem as dinâmicas criminais em determinados âmbitos sociais, a relação da criminalidade com a pobreza e as periferias urbanas e o fenômeno dos grupos delinquentes, assim como trabalhos que problematizassem temas que vão desde a questão dos ilegalismos enquanto conceito apto a desconstruir a categoria crime, e a relação ou associação entre o crime e o uso de substâncias como a droga e o álcool, assim como a própria criminalização dessas substâncias como geradora de efeitos sociais e de criminalização secundária de determinados grupos. E ainda, trabalhos sobre os delitos de proximidade e a violência doméstica e a produção e utilização das estatísticas criminais e de pesquisas de vitimização pelas agências de controle do crime e os problemas epistemológicos daí decorrentes.

Vários pesquisadores responderam ao chamado para o dossiê, e os artigos agora publicados expressam a riqueza da produção sobre violência, crime e segurança pública no Brasil. O dossiê se inicia com o artigo "A pacificação e suas tramas: Conflitos em torno da construção de normas sociais em duas favelas cariocas", de Rodrigo de Araújo Monteiro. A partir da sociologia figuracional de Norbert Elias, o autor busca explorar as relações de dominação, poder e as tensões entre moradores, policiais e traficantes em duas favelas do Rio de Janeiro com Unidades de Polícia Pacificadora (UPPs) onde realizou pesquisa de campo. O trabalho ratifica a ideia de favelas como espaços segmentados e marcados por intensas disputas de poder político, econômico e simbólico, e situa os principais personagens deste universo social.

O artigo intitulado "Marco normativo e políticas públicas de enfrentamento à violência contra a mulher: os desafios na efetivação dos direito", de Ana Claudia Cifali, visa analisar os dados registrados de violência doméstica no cenário nacional e os programas de segurança desenvolvidos para dar conta dos conflitos de violência contra a mulher em âmbito doméstico e familiar. Assim, fazendo um recorte sobre a criação de 
políticas públicas que deram atenção ao tema, analisa as recentes respostas estatais ao problema da violência contra a mulher, apontando as estratégias e os desafios encontrados pelo sistema de justiça criminal tradicional.

O trabalho intitulado "Justiça, fianças e representações na Polícial Civil, de Marcus José da Silva Cardinelli, discute as fianças na Polícia Civil do Rio de Janeiro na perspectiva da antropologia jurídica. Segundo o autor, os delegados, ao fazerem seus julgamentos sobre o cabimento e o valor a ser atribuído, levam em consideração a moralidade e o perfil do preso em flagrante, para além do fato praticado. A liberdade possui valores diferentes conforme esse julgamento moral. Assim, com o discurso de "fazer justiça", alguns delegados impõem punições e reatualizam relações de poder.

O artigo de Rodrigo G. de Azevedo e Marcelli Cipriani, intitulado "Um estudo comparativo entre facções: o cenário de Porto Alegre e o de São Paulo", analisa as chamadas facções prisionais, a partir da comparação entre o contexto da cidade de Porto Alegre, que abarca uma multiplicidade desses grupos, e o do estado de São Paulo - que, em termos de domínio, tem como cerne o Primeiro Comando da Capital. Para tanto, se utiliza material coletado a partir de entrevistas com tópicos guia realizadas com apenados alocados no Presídio Central de Porto Alegre, assim como de questionários semiestruturados aplicados a Policiais Militares que atuam nessa instituição prisional e a operadores do sistema de justiça que lidam com a execução penal. São apontadas, de forma exploratória, algumas similitudes e diferenças presentes na realidade carcerária pesquisada e no contexto paulista, a partir de pesquisas realizadas no sistema penitenciário do estado de São Paulo.

No artigo intitulado "Os agentes penitenciários em Minas Gerais: quem são e como percebem a sua atividade”, Victor Neiva Oliveira, Ludmila Mendonça Ribeiro e Luiza Meira Bastos analisam as percepções dos agentes penitenciários mineiros sobre sua trajetória profissional e condições de trabalho. Realizado em Minas Gerais, estado que reúne a segunda maior população carcerária do país e, provavelmente, o maior efetivo de agentes para garantir a ordem nas unidades prisionais, o survey com estes profissionais foi realizado por meio de um questionário eletrônico, que procurou coletar informações múltiplas de forma a construir um panorama sobre quem são os agentes prisionais e como eles percebem as suas atividades.

Vitor Eduardo Alessandri Ribeiro, no artigo "Reforma do controle social na China: antes e depois de 1978", apresenta elementos sobre o processo de reforma de instituições de controle social na China em dois momentos: antes de 1978 e no momento posterior àquele ano até o presente. Empiricamente, a pesquisa apoia-se em evidências documentais tratadas metodologicamente como formas dotadas de significação apenas enquanto referidas ao contexto social mais amplo. Por meio da diferenciação entre os conceitos de polícia (como instituição de Estado) e o policiar (mais amplo, incluindo o conjunto da sociedade), o trabalho demonstra como a reforma do controle social pode ser evidenciada através de renovados esforços de construção institucional.

Os dois últimos artigos do dossiê refletem uma outra vertente da problematização sobre violência, crime e segurança pública no Brasil, a partir de um viés vinculado não às ciências sociais, mas aos estudos de teoria do direito e do Estado e a uma perspectiva tanto de intervenção social quanto de construção de uma teoria crítica da democracia contemporânea e seus limites.

No trabalho intitulado "A inclusão do Relatório Final da Comissão Nacional da Verdade na Formação Policial: Um passo necessário à consolidação democrática”, Bruno Silveira Rigon, Felipe Lazzari da Silveira e Pablo Ornelas Rosa problematizam a possibilidade de inclusão da exigência do estudo do relatório final da Comissão Nacional da Verdade na formação dos agentes das polícias brasileira como mecanismo capaz de neutralizar a permanência autoritária da violência policial ainda presente após o processo de redemocratização.

O dossiê é finalizado com o artigo "Bobbio, Hegel, Marx e a Crise do Direito Democrático", de Tarso Genro. O ex-governador do Rio Grande do Sul e ex-Ministro da Educação e da Justiça nos Governos Lula propõe uma reflexão sobre a obra de Bobbio, a partir do seu livro "O Futuro da Democracia", publicado pela 
primeira vez em 1984, em Roma. As discussões nele propostas - alicerçadas em todo o processo reflexivo de Bobbio - fazem contraponto às teorizações marxistas mais conhecidas sobre as questões do Direito e do Estado, e se projeta para o futuro da experiência democrática, sejam quais forem os seus rumos, nos quadros de uma sociedade capitalista menos injusta ou na transição para uma sociedade pós-capitalista ainda indeterminada.

Além do dossiê, este número da Revista Sistema Penal \& Violência traz ainda um artigo relacionado à linha de Sistemas Jurídicos-Penais Contemporâneos e dois artigos relacionados à linha de Violência, Crime e Segurança Pública. São eles, respectivamente, “A verdade como 'revelação' no processo penal: da gênese inquisitorial ao arbítrio do sistema misto", de Deise Helena Lora; "Criminalidade e vitimização: Avaliando homicídio e suicídio", de Cristiane Silva, Márcia Regina Godoy e Igor Alexandre Clemente Morais; e "Individualismo, violência criminal e a construção social da vida cotidiana", de Albino José Eusébio e Kátia Mendonça.

Acreditamos que os trabalhos reunidos aqui reflitam a preocupação com a necessidade de incorporar ao debate acadêmico do campo dos estudos criminais a pluralidade de recursos teóricos e metodológicos que hoje tornam as ciências sociais no Brasil uma referência internacional nos estudos sobre crime, polícia e justiça, bem como problematizar e refletir sobre questões relevantes para os destinos da democracia no Brasil, e sobre as quais a pesquisa acadêmica tem algo a dizer, tanto para a qualificação do debate público quanto para a busca de respostas a complexos problemas sociais. Uma boa leitura a todos!

RENATO SÉRGIO DE LIMA Vice-Presidente do Fórum Brasileiro de Segurança Pública e Professor da FGV EAESP. Pesquisador de Produtividade do CNPq e coorganizador do livro Polícia e Democracia: 30 anos de estranhamentos e esperanças (Ed. Alameda, 2015). $<$ r.rsdlima@gmail.com>

RODRIGO GHIRINGHELLI DE AZEVEDO Conselheiro do Fórum Brasileiro de Segurança Pública e Professor da PUCRS. Pesquisador de Produtividade do CNPq e membro do Instituto Nacional de Estudos Comparados em Administração de Conflitos (INEAC). <rodrigo.azevedo@pucrs.br>

Submetido em: 13/12/2015.

Aceito em: 14/12/2015. 